\title{
28 Research Square \\ Fetal Reduction in High Order Pregnancy; A Retrospective Observational Study
}

Manal shaker taha ( $\square$ manalstaha@gmail.com )

women's wellness and research center

Abdullah Al Ibrahim

women's wellness and research center

Olubusola Amu

women's wellness and research center

Sawsan Al-Obaidly

women's wellness and research center

Prem Chandra

Hamad Medical Corporation

Zeena Al mansorri

women's wellness and research center

Najat Kenyab

women's wellness and research center

Najah Al-Janahi

women's wellness and research center

\section{Research Article}

Keywords: fetal reduction, High order multiple pregnancy, quadruplets

Posted Date: April 19th, 2021

DOI: https://doi.org/10.21203/rs.3.rs-396185/v1

License: (c) (1) This work is licensed under a Creative Commons Attribution 4.0 International License.

Read Full License 


\section{Abstract}

\section{Background:}

High order multiple pregnancy (HOMP), is considered a high-risk pregnancy as it has many complications on the mother and the fetuses, with a huge financial burden on the hospitals. Therefore avoiding HOMP is important, however, if this fails, fetal reduction is an acceptable alternative procedure to reduce maternal complications and improve fetal outcome.

Our aim to study the impact of a fetal reduction on the risk of preterm labour and postpartum hemorrhage in HOMP (More than Triplet).

\section{Methods:}

This is a retrospective study of all HOMPs seen during the period from July 2007 to July 2017 at Women's Hospital- Hamad General Hospital, Doha, Qatar. We examined records of 50 women diagnosed with HOMP, incomplete records, and triplet pregnancies were excluded from the study. the data were collected from the ultrasound software as well as maternal files.

\section{Results:}

Of the 50 women diagnosed with HOMP, 39 quadruplets, 7 quintuplets. 2 sextuplets and 2 septuplets. $56 \%$ had an ovulation induction, $26 \%$ had an IVF, $14 \%$ had an IUI, and 2 cases (4\%) were spontaneous pregnancies.

$(28 \%)$ had a fetal reduction, with a mean gestation age of $12.64 \pm 0.74$ weeks of gestation, and with no immediate complications.

Our study showed that there is no significant difference at time of delivery between reduced and non reduced group mean gestational age at the time of delivery for the reduced group was $30.26 \pm 4.38$, and $29.39 \pm 4.78$ weeks for the non-reduced group. P-value of $0.565,95 \% \mathrm{Cl}(-2.159-3.90) .44 .9 \%$ had postpartum haemorrhage with a mean estimated blood loss of $1659.1 \pm 958.5 \mathrm{mls}$. Our study showed that there is significant decrease in estimated blood loss in reduced group compared with non-reduced group with p-value of 0.047

\section{Conclusion}

High order multiple pregnancies are a result of modern infertility treatments has significant serious adverse effects on the mother and the babies. Although fetal reduction reduced the rate of PPH but did not significantly improve the rate of preterm labour, hence prevention of HOMP is the primary goal.

\section{Introduction}


Higher-order (triplet or more) multiple pregnancies occur when more than two fetuses are present in the uterus at the same time. (1) (2)

High order multiple pregnancies (HOMP) are uncommon, the reported incidence range from $0.01 \%$ to $0.07 \%$ of all pregnancies.(1) (2) (3)

Spontaneous quadruplet pregnancy is rare with an incidence rate of 1 in 512000 to 1 in 677,000 births (2)

The incidence of multiple pregnancies has increased dramatically in the last 25 years (4) (5)

In United States it is documented that HOMP has increased fourfold during the 1980s and 1990s (6), due to infertility treatments like Assisted Reproductive Techniques (ART) and ovulation-inducing treatments (7) (8)

The lack of insurance coverage for ART in most of the United States, as well as competition among ART programs, has generated pressure to achieve success in a minimal number of cycles, one strategy has been to increase the number of embryos transferred per IVF procedure. (9)

An analysis of 1998 Society of Assisted Reproductive Technology (SART) data demonstrated that providers in states without insurance coverage for IVF transferred more embryos per cycle, had a higher percentage of cycles resulting in pregnancy, and encountered an increased frequency of high order gestations compared to providers in states with IVF insurance coverage (9).

HOMP is considered a high-risk pregnancy as it has many complications on the mother and the fetuses with marked psychosocial and economical implications.

Prenatal morbidities as prematurity ( more than 90\% deliver prematurly) (2), intrauterine growth restriction, low-birth weights for these babies, congenital malformation have been showing to be more common in HOMP (7) . Long term consequences for these fetuses as cerebral palsy and learning disabilities are demonstrated.(8)

Complications of prematurity as Intraventricular hemorrhage, periventricular leukomalacia, cerebral palsy, necrotizing enterocolitis, retinopathy of prematurity, and respiratory distress syndrome which can result in permanent injuries, including cerebral palsy, mental retardation, chronic lung disease, and loss of vision and hearing. (5) $\square$ maternal mortality associated with multiple births is 2.5 times that for singleton births (10)

Maternal morbidities such as pre-eclampsia, anaemia, postpartum haemorrhage which is more than 500 $\mathrm{ml}$ blood loss.. etc. are higher in HOMP and up to three to seven times more common than singleton pregnancies (8), and these complications usually associated with consequently prolonged hospitalization. $\square$ 
It is difficult for the parents to take care of four or five babies at the same time, and it was found that depression is more common in mothers of multiple births, and they are more emotionally and physically exhausted than a singleton pregnancy. (11). These pregnancies constitute a huge financial burden for the hospitals, data shows that the average cost per multiple gestation delivery is greater than the average cost of in-vitro fertilization (IVF) and intracytoplasmic sperm injection (ICSI) cycles (8).

A study by (12) showed that the mean hospital costs of a singleton, twin, and HOMP child to age 5 years were \$2730, \$8993, and \$24 411 (in 2009-2010 US dollars), respectively, with cost differences concentrated in the neonatal period and during the first year of life. Almost $15 \%$ of inpatient costs for multiple births could have been avoided if ART twins and HOMP had been born as singletons. (12)

Avoiding HOMP is important, therefore changes in assisted reproductive technologies (ART) practices, such as reducing the number of embryos transferred in ART procedures, using lower doses of ovulation induction medications or if multiple mature follicles seen during ovulation induction the cycle will be cancelled, all these modifications have been associated with the decline in higher-order multiple births (8) if primary prevention of HOMP failed, the fetal reduction is an ethically acceptable procedure (13) and its appropriate alternative to decrease the perinatal morbidity and mortality and to increase survival and well-being of high order pregnancy (14)

The term selective reduction means the selective termination of one or more embryos, using a transabdominal or trans-vaginal approach, under careful real-time ultrasonographic monitoring. The operation usually is performed late in the first trimester or early in the second trimester, commonly, no more than two embryos are terminated at one session, and occasionally a second intervention is indicated.

In United States the triplet and higher-order birth rate declined from about 1 in 515 births in 1998 to one in 880 births in 2014 and that decline was around 41\% (6)

National Vital Statistics System data in United States of 2015 reported the number of quadruplet births were 228 and the number of quintuplets and other higher-order births were 24 , with the rate of triplet or higher-order birth were: 103.6 per 100,000 live births, while in 2018 they reported that the number of quadruplets were 217 , higher-order multiple birth rate was 101.4 per 100,000 births for 2016, a nonsignificant decline from 2015 (15), but with the marked decline in HOMP since the peak 1998 (16)

The outcome of HOMP was determined by the gestational age at delivery,(5), the mean gestational age at delivery for quadruplet pregnancies was reported to be 31.4 weeks (5)

HOMP are best to be managed in a tertiary centre, and with aim of prolongation the gestation time as much as possible, thereby allowing the medical team to deliver the fetuses safely and to have advanced neonatal intensive care unit. (4)

Term delivery is rare in quadruplet pregnancies because of the increased risk of preterm delivery and other pregnancy complications such as pre-eclampsia and preterm premature rupture of fetal membranes 
. (2) , It is stated that the average gestational age at delivery for twins is 35 weeks, triplets 32.2 weeks quadruplets 29.9 weeks, and quintuplets 28.5 weeks (2)

Prevention and management of HOMP, therefore, poses a great challenge to the obstetrician as there is no clear evidence-based approach to its management and prevention, bed rest, beta mimetic drugs, progestogens, and elective cervical cerclage have all been reported to have a beneficial effect in prolonging pregnancy in some literature, but the results are yet to be substantiated by controlled trials. (2)

There are limited studies are reviewing obstetric outcomes following fetal reduction. $\square$

Our aim retrospectively to review the outcomes of fetal reduction in HOMP in reducing the risk of post partum haemorrhage (PPH) and preterm labour in quadruplets and quantuplets pregnancies.

\section{Materials And Methods}

\section{Study design and study area:}

It is a retrospective study, conducted in Obstetrics and Gynaecology Department, Women's Hospital, currently known as Women's Wellness and Research Center, Hamad Medical Corporation, Doha, Qatar. it is a governmental hospital and the largest women's tertiary hospital in the country with average deliveries of 17,000 births per year. it has 7 operating theatres and 26 delivery rooms.

\section{Study sample:}

The study sample included all medical records of 50 women diagnosed with HOMP (defined is more than triplets) who had antenatal care and gave birth in the hospital in the period from July 2007-July 2017, however incomplete records, triplets pregnancy were excluded from the study

The data were collected from the ultrasound software (Astraia Software GmbH Occamstr. 20, 80802 Munich Germany) and maternal records for pregnancy progress, fetal complications, and maternal comorbidities, and delivery outcome.

The Data was kept in a password-protected Excel sheet (C 2010 Microsoft Corporation).

\section{Data extraction}

The records included information on subjects' demographics age, chorionicity, mode of conception, parity, maternal diseases, if the fetal reduction was done, and at which gestation? time of delivery, mode of delivery, the indication of delivery and estimated blood loss during delivery

\section{Statistical analysis}

Descriptive analysis of mean \pm standard deviation (SD), median, minimum and maximum for continuous variables were performed using SPSS version 20.0 
Comparisons were done using T-test, ANOVA, and chi-square test.

$95 \% \mathrm{Cl}$ was used to assess the statistical significance of association among variables, with a $\mathrm{P}$ value less than 0.05 was used as a cut off point to see the presence of a statistically significant association.

\section{Ethical considerations}

Ethical clearance for the study was obtained from the Medical Research Center,(MRC), Hamad Medical Corporation (HMC), Doha- Qatar, Ref No: MRC0419/2017. To protect the patient confidentiality, the identifiable information as name of the patients and health number was excluded from the extracted data and replaced with specific code generated for the study.

\section{Results}

During the study period a total of 50 pregnant women diagnosed with HOMP and gave birth in women's hospital, of these women 39 (78\%) had quadruplets pregnancy, 7 (14\%) had quintuplets, 2 (4\%) had sextuplets, and 2 (4\%) had septuplets pregnancy, with more than $95 \%$ of them conceived through ART. The mean maternal age was 30 years . $13(26 \%)$ were nulliparous and $37(74 \%)$ were multiparous, with no family history of multiple pregnancies before in $96 \%$ of them (Table 1 ).

Table 1, obstetric profile of women with HOMP 


\begin{tabular}{|lll|}
\hline Characteristics & Mean \pm SD & Median (min- max) \\
\hline Age & $30.60 \pm 4.87$ & $30.25(19.40-39.30)$ \\
\hline Chronicity & \\
Quadruplets & $39(78 \%)$ \\
Quintuplet & $7(14 \%)$ \\
Sextuplets & $2(4 \%)$ \\
Septuplets & $2(4 \%)$ \\
\hline Mode of conception & \\
Ovulation induction & $28(56 \%)$ \\
IVF & $13(26 \%)$ \\
IUI & $7(14 \%)$ \\
Spontaneous & $2(4 \%)$ \\
\hline Parity & \\
Nuliparus & $13(26 \%)$ \\
Multiparus & $37(74 \%)$ \\
\hline Previous miscarriages & $48(96 \%)$ \\
No & $33(66 \%)$ \\
Yes & $17(34 \%)$ \\
\hline Previous Multiple pregnancy & \\
No & $41(83.7)$ \\
Yes & \\
\hline Family Hx of multiple pregnancy & \\
\hline No & \\
\hline
\end{tabular}

Table 2, outcomes of HOMP 


\begin{tabular}{|ll|}
\hline Fetal reduction & $31(62 \%)$ \\
No & $14(28 \%)$ \\
Ses & $5(10 \%)$ \\
\hline Number of fetuses reduced & \\
1 fetus & $7(36.8 \%)$ \\
2 fetuses & $9(47.4 \%)$ \\
3 fetuses & $3(15.8 \%)$ \\
\hline Gestational age for fetal reduction & $12.64 \pm 0.74$ \\
\hline Mode of delivery & $12.7(11-14)$ \\
LSCS & $44(88 \%)$ \\
Miscarriage & $4(8 \%)$ \\
ND & $2(4 \%)$ \\
\hline Indication of delivery & \\
Emergency & $35(70 \%)$ \\
Elective & $11(22 \%)$ \\
Miscarriage & $4(8 \%)$ \\
\hline PPH & $27(54.1 \%)$ \\
No & $1659.1 \pm 958.5$ \\
\hline Amos & $1400(1000-5000)$ \\
\hline
\end{tabular}

\section{Time of delivery in HOMP:}

We had 28 women who delivered quadruplets, mean gestational age at the time of delivery for quadruplets was $30.38 \pm 2.66$ weeks with $95 \% \mathrm{Cl}$ (29.35-31.42) , Three women delivered quintuplets, mean gestational age at the time of delivery for quintuplets was 31.67 weeks gestation with $95 \% \mathrm{Cl}$ (25.42-37-92) , using ANOVA, there is no statistically significant difference at the time of delivery between quadruplets and quintuplets (ANOVA F= 1.09, P-value $=0.346$ )

Fetal reduction and timing of delivery: 
There were 14 women had fetal reduction 31 women didn't have fetal reduction, mean gestational age of fetal reduction 12 weeks (Table 2), with no immediate post-operative complications.

Mean gestational age at the time of delivery for reduced group was $30.26 \pm 4.38$, and $29.39 \pm 4.78$ weeks for non-reduced group respectively. Using T-test to compare the 2 groups we found that there is no statistically significant difference between reduced and non-reduced group with a P-value of $0.565,95 \%$ $\mathrm{Cl}(-2.159-3.90)$, the difference of the mean was found to be 0.87 .

\section{Fetal reduction and post partum haemorrhage}

Table 3, Chi-square test of fetal reduction of pregnancy and PPH

\begin{tabular}{|c|c|c|c|c|c|}
\hline \multicolumn{3}{|c|}{ Fetal reduction Vs $\mathrm{PPH}$} & \multicolumn{2}{|l|}{$\mathrm{PPH}$} & \multirow[t]{2}{*}{ Total } \\
\hline & & & No & Yes & \\
\hline \multirow[t]{4}{*}{ Fetal reduction } & \multirow[t]{2}{*}{ No } & Count & 14 & 16 & 30 \\
\hline & & \% Within PPH & $56.0 \%$ & $84.2 \%$ & $68.2 \%$ \\
\hline & \multirow[t]{2}{*}{ Yes } & Count & 11 & 3 & 14 \\
\hline & & \% Within PPH & $44.0 \%$ & $15.8 \%$ & $31.8 \%$ \\
\hline \multirow{2}{*}{\multicolumn{2}{|c|}{ Total }} & Count & 25 & 19 & 44 \\
\hline & & \% Within PPH & $100.0 \%$ & $100.0 \%$ & $100.0 \%$ \\
\hline
\end{tabular}

Table 3, shows, $84.2 \%$ of the group who didn't have fetal reduction had PPH, On the other hand $15.8 \%$ of the group who had fetal reduction had PPH. Using Chi-square test there is significant decrease in PPH in reduced group with $p$-value of 0.047

\section{Maternal co-morbidities}

Women who were fit and healthy without any maternal co-morbidities were 23 (46\%) women, and women with 1 or 2 maternal comorbidities were 27 (54\%)

Maternal comorbidities include asthma, hypothyroidism, gestational diabetes, hypertension with pregnancy, iron deficiency anemia, and high body mass index.

\section{Congenital anomalies:}

Table 4, congenital anomalies with the description of the anomalies 


\begin{tabular}{|c|c|c|c|c|c|}
\hline $\begin{array}{l}\text { Type of } \\
\text { pregnancy }\end{array}$ & $\begin{array}{l}\text { Number } \\
\text { of fetuses } \\
\text { affected } \\
\text { with } \\
\text { anomalies }\end{array}$ & $\begin{array}{l}\text { Affected } \\
\text { organ }\end{array}$ & Chorionicity/Amnionicity & $\begin{array}{l}\text { Description of } \\
\text { anomalies }\end{array}$ & Outcome \\
\hline \multirow[t]{2}{*}{$\begin{array}{l}\text { Quadruplets } \\
\text { pregnancy }\end{array}$} & 1 fetus & Heart & $\begin{array}{l}\text { Monochorionic- } \\
\text { diamniotic }\end{array}$ & $\begin{array}{l}2 \text { pulmonary } \\
\text { veins draining in } \\
\text { left atrium, } \\
\text { dilated right } \\
\text { atrium, abnormal } \\
\text { tricuspid valve, } \\
\text { thick pulmonary } \\
\text { valve, with post } \\
\text { stenotic } \\
\text { dilatation, normal } \\
\text { left side heart }\end{array}$ & $\begin{array}{l}\text { Stage III } \\
\text { TTTS at } \\
18+ \\
\text { weeks. } \\
\\
\text { IUFD for } \\
\text { the donar } \\
\text { at } \\
29+\text { weeks. }\end{array}$ \\
\hline & & & & & $\begin{array}{l}\text { Had LSCS } \\
\text { at } \\
35+\text { weeks }\end{array}$ \\
\hline $\begin{array}{l}\text { Quadruplets } \\
\text { pregnancy }\end{array}$ & 1 fetus & $\begin{array}{l}\text { Head } \\
\text { and } \\
\text { spine }\end{array}$ & $\begin{array}{l}\text { Monochorionic- } \\
\text { diamniotic }\end{array}$ & $\begin{array}{l}\text { With } \\
\text { polyhydramnios, } \\
\text { lumber Spina } \\
\text { bifida and dilated } \\
\text { ventricles. }\end{array}$ & $\begin{array}{l}\text { LSCS at } \\
28 \text { weeks }\end{array}$ \\
\hline
\end{tabular}

\section{Discussion}

The prevalence of infertility is estimated to be around $9 \%$ worldwide. The fact that fertility declines with age, as well as the trend toward later child-bearing, with more women over 30 years of age giving birth, may contribute to an increased number of ART cycles worldwide (17)

After excluding incomplete data and lost follow-up, we had 50 women had HOMP with the mean age of 30 years old. With a $74 \%$ of them where Multiparus ( had 1 child or more before)

Multiple births are much more common today than they were in the past, as a result of Assisted Reproductive Technologies. And the associated fetal and maternal complications are significantly high compared to the singleton and twins.

We showed how ART overwhelmingly contributed on the conception of HOMP with up to $95 \%$ conceived through some form of ART, the fact that has been addressed by other authors (18) .

HOMP are at extremely high risk for complications and morbidity. The single most important risk factor is preterm labor. The specter of very early preterm delivery followed by prolonged admission to a neonatal intensive care unit and all the possible sequelae thereof have led some clinicians to offer fetal reduction, even in the absence of known genetic disease or anatomic deformity demonstrated by ultrasound (19), aiming to reduce the number of fetuses and to prolonge the pregnancy to decrease the complications of preterm delivery. 
In our study mean gestational age of preterm delivery was 31 weeks, which is similar to Suri et al (20).

Clinicians should realize that there are significant emotional challenges for couples undergoing multifetal pregnancy reduction. Many of these couples are long-standing infertility patients who find this procedure opposite to their reproductive desires (19)

It is worth mentioning that fetal reduction did not significantly improve the preterm delivery rate. this is similar to observations made by Alexander, J et al (21), however, its different than Abel et al (22) who concluded fetal reduction in quadruplets is associated with decreased early prematurity. And the overall survival is higher after reduction,. Many factors might contribute to such differences in the studies, including the initial number of fetuses, the maternal comorbidities, and the fact that our study mainly includes those HOMP > triplets, while Abel's study includes only 10 cases of Quadruplets.

Postpartum hemorrhage is cumulative blood loss of greater than or equal to $1000 \mathrm{ml}$ of blood loss (17) sequelae of hemorrhage include adult respiratory distress syndrome, shock, disseminated intravascular coagulation, acute renal failure, loss of fertility. And pituitary necrosis ( Sheehan syndrome). (17). PPH was encountered in almost half of the patients mainly due to overdistension of the uterus which affects the uterine contractions, fetal reduction however significantly reduced the rate of $\mathrm{PPH}$, which in our opinion is a quite important result, considering the short and long term risks associated with PPH. In fact, this notion was not specifically addressed in other studies.

For HOMP, vaginal deliveries have been reported, but the problems associated with them suggest that elective caesarean section may be the ideal route of delivery. (19). In our study caesarean section was mode of delivery in almost $90 \%$ of the cases with mean blood loss of (1659.1 $\pm 958.5 \mathrm{ml})$, which is another risk of HOMP with all risks during surgery as injury to internal organs, thrombosis, longer hospital stay and the subsequent risks in future pregnancies, including placenta previa and accreta .

The caesarean section should be executed by a team of experienced obstetricians capable of performing a hysterectomy in case of an intractable postpartum hemorrhage. Moreover, an experienced anesthesiologist with sufficient support staff should be available. (19)

Table 4, show the congenital anomalies, we had 2 pregnancies complicated with congenital anomalies, and both pregnancies were monochorionic- diamniotic which is known to increase the risk of congenital anomalies.

\section{Strength And Limitations}

There are some limitations to acknowledge, first due to the retrospective character full information about the pre-existing medical condition and pregnancy-related health issues could be incomplete, secondly, detailed anomaly scans for all the fetuses was difficult to perform so we believe the number of congenital anomalies could be under-reported and finally, lack of neonatal data as neonates have separate files and not linked with the mother's files. 
The major strength of our study is that the women were seen in a tertiary centre, which help obtaining the data from one source, additionally we had high number of such rare pregnancy complication as we didn't include the triplet pregnancy unlike previous other studies in HOMP, finally availability of the fetal reduction option, which help in making comparison.

In saying that, it is a call for well-designed prospective research to address the above issues with a more profound approach.

\section{Conclusion}

High order multiple pregnancies are a result of modern infertility treatments has significant serious adverse effects on the mother and the babies.

The ideal treatment for infertility would raise the expectation that high rates of pregnancy which automatically lead to high rates of multiple pregnancy.

Women of HOMP should be counselled about all the possible complications associated with carrying the pregnancy and should be provided information about the availability of fetal reduction. And she should be informed that it's a safe procedure in experienced hands but that there will always be a small risk for losing the entire pregnancy.

Although fetal reduction reduced the rate of PPH but did not significantly improve the rate of preterm labour, hence prevention of HOMP is the primary goal.

\section{List Of Abbreviations}

\begin{tabular}{ll} 
HOMP & High order multiple pregnancy \\
\hline IVF & In vitro fertilization \\
\hline IUI & Intrauterine insemination \\
\hline PPH & Postpartum haemorrhage \\
\hline CI & Confidence interval \\
\hline ART & assisted reproductive techniques \\
\hline LSCS & Lower segment caesarean section \\
\hline ND & Normal delivery \\
\hline SD & Standard deviation \\
\hline IUFD & Intrauterine fetal death \\
\hline TTTS & Twin to twin transfusion syndrome
\end{tabular}




\section{Declarations}

\section{Acknowledgement}

Thanks to Dr.Midhat hassanin and Dr.Isacc for their support and advice.

competing interest: the authors have no financial or non-financial interests to declare in relation to this article.

\section{Contribution to authorship:}

All authors contributed in planning and conducting the study, SO and AE applied for the approval, MST collected the data ,data analysis done by PC , AE , OA, SO contributed in the interpretation of the data, MST wrote the first draft, and revision done by $A E, O A, P C$ and $S O$

All authors approved the final version for submission.

\section{Ethical approval:}

The research related to human use has been compiled with all relevant national regulations. Institutional policies and in accordance with the tenets of the Helsinki declaration. The study has been approved by the local institutional review board at Medical research center (MRC), Hamad Medical Corporation, DohaQatar, reference No: MRC0419/2017. Informed consent was waived due to the retrospective design of the study.

To protect the patient confidentiality, the identifiable information as name of the patients and health number was excluded from the extracted data and replaced with specific code generated for the study.

\section{Funding:}

No financial support was obtained for research or publication.

\section{Availability of data and materials:}

The data of the current study are available from the corresponding author on reasonable request.

\section{References}

1. Setu Rathod, Sunil Kumar Samal SS, Sujata Swain. Quadruplet Pregnancy Following Spontaneous Conception: A Rare Case Report. 2015. p. 1-2.

2. Nnadi D, Ibrahim A, Nwobodo E. Case Report Spontaneous Monochorionic Tetra - amniotic Quadruplet Pregnancy at Term. J Basic Clin Reprod Sci. 2013;2(1):57-60.

3. Umeora O U J, AneziOkoro E A EVE. Higher-order multiple births in Abakaliki, Southeast Nigeria. Singapore Med J. 2011;52(3):163-7. 
4. Dera A, Szymankiewicz M, Ropacka-lesiak M, Markwitz W. Variable Outcome in Quintuplets Pregnancy Based on Obstetric Care. Twin Res Hum Genet. 2017;14(6):580-5.

5. Elliott JP. High-Order Multiple Gestations. Semin Perinatol. 2005;29(5):305-11.

6. Martin JA, Osterman MJK, Thoma ME. Declines in Triplet and Higher-order Multiple Births in the. 2016;(243):1-8.

7. Adegbite AL, Ward BS, Bajoria R. Perinatal outcome of quadruplet pregnancies in relation to chorionicity. J Perinatol. 2007;15-21.

8. Commenda V, Steirteghem A Van. Multiple gestation pregnancy. Hum Reprod. 2000;15(7):1856-64.

9. Wendy Kuohung, Elizabeth S Ginsburg CR. Strategies to control the rate of high order multiple gestation - UpToDate

10. NICE. Multiple pregnancy: antenatal care for twin and triplet pregnancies. Clinical guideline CG129. 2011;(September 2011).

11. Thorpe K, Golding J, Macgillivray I, Greenwood R. Comparison of prevalence of depression in mothers of twins and mothers of singletons. BMJ. 1991;302:875-8.

12. Chambers GM, Van Hoang P, Lee E, Hansen M, Sullivan EA, Bower C, et al. Hospital costs of multiplebirth and singleton-birth children during the first 5 years of life and the role of assisted reproductive technology. JAMA Pediatr. 2014 Nov 1;168(11):1045-53.

13. Drugan A, Weissman A. Multi-fetal pregnancy reduction (MFPR) to twins or singleton - medical justification and ethical slippery slope. J Perinat Med. 2017 Jan 1;45(2):181-4.

14. Zipori $Y$, Haas J, Berger $H$, Barzilay E. Multifetal pregnancy reduction of triplets to twins compared with non-reduced triplets: a meta-analysis. Reprod Biomed Online. 2017 Sep ;35(3):296-304.

15. Martin JA, Brady MPH; , Hamilton E, Osterman MJK, Driscoll AK; Drake P. National Vital Statistics Reports Volume 67, Number 1, January 31, 2018. 2016

16. Martin JA, Hamilton BE, Ph D, Osterman MJK, Driscoll AK, Ph D. National Vital Statistics Reports Births: Final Data for 2015. 2017;66(1):1-70.

17. Shields LE, Goffman D, Caughey AB. Practice Bulletin No. 183: Postpartum Hemorrhage. Obstet Gynecol. 2017 Oct $1 ; 130(4): \mathrm{e} 168-86$.

18. Kulkarni AD, Jamieson DJ, Jones HW, Kissin DM, Gallo MF, Macaluso M, et al. Fertility Treatments and Multiple Births in the United States. N Engl J Med. 2013 Dec 5;369(23):2218-25.

19. Keith LG. Higher-Order Multiple Gestations. Glob Libr Women's Med. 2009;

20. Suri K, Bhandari V, Lerer T, Rosenkrantz TS, Hussain N. Morbidity and mortality of preterm twins and higher-order multiple births. J Perinatol. 2001 Sep 4;21(5):293-9.

21. Alexander JM, Hammond KR, Steinkampf MP. Multifetal reduction of high-order multiple pregnancy: Comparison of obstetrical outcome with nonreduced twin gestations. Fertil Steril. $1995 \mathrm{Dec}$ 1;64(6):1201-3.

22. Abel JS, Flöck A, Berg C, Gembruch U, Geipel A. Expectant management versus multifetal pregnancy reduction in higher order multiple pregnancies containing a monochorionic pair and a review of the 
literature. Arch Gynecol Obstet. 2016 Nov 1;294(6):1167-73. 